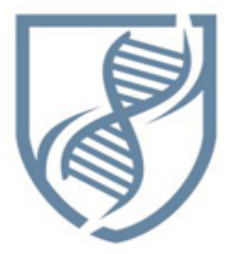

Journal of Bioscience and Applied Research

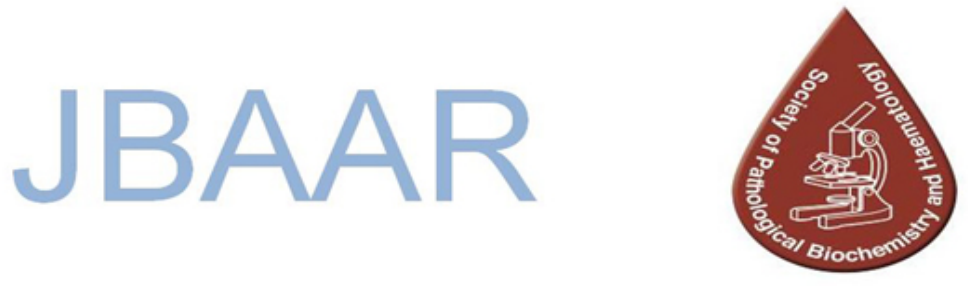

WWW.JBAAR.ORG

\title{
Teratogenicity of sodium fluoride on newly born rats
}

\author{
Abdelalim A. Gadallah ${ }^{1,2}$ \\ ${ }^{1}$ Zoology Dept., Faculty of Science, Mansoura University, Egypt \\ ${ }^{2}$ Preparatory Year Deanship, Jazan University, Kingdom of Saudi Arabia \\ (Corresponding author e.mail:abdelalimg@gmail.com)
}

\begin{abstract}
Fluoride (F) is widely used to sterile drinking water against bacterial infection as well as for normal cleaning of teeth. Although intake of low doses of fluoride is required to prevent dental caries, increased uptake for long time injured bone and soft tissues causes fluorosis (Susheela, 1999). The present study aims to illustrate the teratogenicity and histopathological alterations of fluoride in maternal liver, kidney and thyroid glands. Twenty virgin female and male albino rats of Wistar strain at ratio of 2 female/ 1male were kept under good ventilation with controlled conditions and excess food and water were supplied ad libitum. Pregnant rats were arranged into two groups ( $n=6)$ including, control and fluoride-intoxicated group. Body weight, size and crown rump length of newly born rats were determined. The offspring 1-day old were sacrificed by light anesthesia with diethyl ether and immediately fixed in $10 \%$ formal saline. Alizarin red S preparation of both control, and experimental groups were made and the incidences of deformed bones were recorded. Histological preparations of maternal liver, kidney and thyroid glands were made and examined under bright field light microscopy. Experimental group exhibited disruption of the normal integrity of hepatic lobules with prominent centrilobular necrosis and dilatation of blood sinusoids. Perivascular leukocytic cell infiltration was remarked with bile duct obliteration. Also, peritubular inflammatory cellular infiltration associated with degeneration of renal tubular lining epithelial cells and reduction of their tubular lumina were also detected. Degeneration of the thyroid follicles with marked reduction and vacuolation of colloid. Few numbers of the thyroid follicles exhibited exfoliation of their lining cells within their follicular lumina. Interfollicular hemorrhage and congested blood vessels were remarked. Fluoride-intoxication showed abortion of one $/ 6$ mothers. There were numerical decreases of offspring of fluoride-intoxicated mother . Increase average of congenital malformations was observed.
\end{abstract}

Keywords:Fluoride-toxicity,liver,thyroidgland,kidney, mother,offspring

\section{Introduction}

Fluoride $(\mathrm{F})$ is a widely used to sterile drinking water against bacterial infection as well as for normal cleaning of teeth. Although intake of low doses of fluoride is required to prevent dental caries, increased uptake for long time injured bone and soft tissues causes' fluorosis (Susheela, 1999). Also, Fluoride is a highly reactive inorganic mineral and forms numerous inorganic compounds. It is widely used in manufacture of wire and cable insulations, pipe lining, rodenticides, refrigerants, aerosol propellants, fertilizer, and electronic ceramics (Pratusha et al., 2011). On the other hand, exposure to high concentration of $\mathrm{F}$ was found to interfere with dysfunction of teeth and bones. F was found to induce induced apoptosis of epithelial lung cells (Thrane et al., 2000). F intoxications were reported in many organs such as heart, liver, kidneys, gastrointestinal tract, lungs, brain and blood (Perumal et al., 2013). Occupational hazards of fetotoxicity of fluoride were reported since water fluoridation was initiated in the 1940s. Tadpole exposed to sodium fluoride was found to develop reduction in the head-tail lengths and dysfunction of the neuromuscular system (Goh and Neff, 2003). In vitro studies of fluoride toxicities on limb bud cells of 13-day rat (6.8 micrograms $/ \mathrm{ml}$ ) and 12-day mouse (7.3 micrograms/ml) for 5 days were found to inhibit cell proliferation and differentiation (Zhang and Wu, 1998). Expose rats (Gupta et al., 2007; Kumar et al., 2010) and mice (Sun et al., 2011) to fluoride in drinking water were found to increase the incidence of infertility and reduce sperm counts. There is a little of work concerned maternal fluoride toxicities.

The present study aims to illustrate the teratogenicity and histopathological alterations of fluoride in maternal liver, kidney and thyroid glands. 


\section{Materials and Methods}

Twenty virgin female and male albino rats of Wistar strain (body weight: $145 \pm 3.1 \mathrm{~g}$ ) at ratio of 2 female/1male were provided from Hellwan Breading farm (Ministry of Health, Egypt). They were kept under good ventilation with controlled conditions (12 hr light/ dark cycle; $22-24{ }^{\circ} \mathrm{C}$ ) and excess food and water were supplied ad libitum. Pregnancy was carried out by mating fertile male with virgin female for overnight and examination of vaginal smears on the next morning to determine the onset of gestation. Pregnant rats were arranged into two groups $(n=$ 6) including, control and fluoride-intoxicated group (20 $\mathrm{mg} / \mathrm{kg}$ body weight in tap water, dosed orally from 6th day of gestation till parturition). The animals were sacrificed at parturition according to the bioethics of Mansoura University Committee. Body weight, size and crown rump length of newly born rats were determined. The offspring 1-day old were sacrificed by overdose of chloroform and immediately fixed in $10 \%$ formal saline. Skeleton preparation of both control, and experimental groups were made by treatment with $2 \%$ potassium hydroxide until ossified areas were clearly visible through the soft tissue and stained by the alizarin red "S" method. The incidences of deformed bones were recorded. Maternal liver, kidney and thyroid glands were incised and fixed in $10 \%$ formal saline, dehydrated in ascending grades of ethyl alcohol, cleared in xylene and mounted in molten paraplast $58-62^{\circ} \mathrm{C}$. Five microns histological sections were cut and stained with hematoxylin and eosin and examined under bright field light microscopy.

Biostatistics: The significance test for differences between the control and fluoride-intoxicated group was determined. $P$ value of $<0.05$ means significant.

\section{Results}

\section{Maternal liver, kidney and thyroid gland:}

Liver: Control liver possessed normal hepatic strands arranged around the central vein with thin blood sinusoids and fine arrangement of Kupffer cells (Fig.1A). Experimental group received daily oral doses of fluoride $(20 \mathrm{mg} / \mathrm{kg}$ body weight) from 6th day of gestation till parturition exhibited disruption of the normal integrity of hepatic lobules with prominent centrilobular necrosis and dilatation of blood sinusoids. Perivascular leukocytic cell infiltration was remarked with bile duct obliteration. Granulomatous lesions were detected (Fig.1 A1\&A2).

Kidney: Normal kidney showing normal structure of glomeruli with intact Bowman's capsule and renal tubules lined with epithelium (Fig.1 B). Fluoride intoxicatiion exhibited peritubular inflammatory cellular infiltration associated with degeneration of tubular lining epithelial cells and reduction of their tubular lumina. Glomerulonephritis characterized by reduced Bowman's space were observed in many of the nephron. Peri-glomerular round cell infiltration was also detected (Fig.1 B1\&B2).

Thyroid gland: Control exhibited the presence of follicles of varying sizes outlined by cubical follicular cells with rounded vesicular nuclei. Their lumina were enclosed by homogenous eosinophilic colloid material. The interfollicular cells and blood capillaries occupied the space between thyroid follicles. The follicles were separated by thin collagen fibers (Fig. 1C). In experimentally group intoxicated with fluoride, there was a detected degeneration of the follicles with vacuolation and reduction of colloid. Few numbers of the thyroid follicles exhibited exfoliation of their lining cells within their follicular lumina. Inter-follicular haemorrhage and congested blood vessels were observed. The follicular epithelium appeared either vacuolated or entirely degenerated (Fig. 1 C1\&C2).

\section{Effects on pregnants:}

Fluoride-intoxication showed abortion of one /6 mothers. There were numerical decreases of their offspring. Increase average of congenital malformations was observed. Most of the malformations were restricted mainly in fore \& hind limb deformation, reduced neck region and kyphosis. Missing ossification of distal phalanx of fore \& hind limb and caudal vertebrae. Decreased body weight, size and crown-rump length were also observed (Table 1 \& Figs. 2 \&3).

\section{Discussion}

Fluoride-intoxication represents one of the important public health problems. Oral intake of sodium fluoride (20 $\mathrm{mg} / \mathrm{kg}$ body weight) from 6th day of gestation till parturition exerted histopathological lesions in liver, kidney and thyroid gland of mother rats. Nephrotoxicities manifested by tubular necrosis and glomerulonephritis, meanwhile centrilobular necrosis and granulomatous lesions were mainly detected liver. Massive atrophy of thyroid follicles with almost loss of their thyroglobulin and degeneration of follicle epithelium were remarked

Similar studies explained the fluoride associated hepatotoxicity (Shashi and Thapar,2000; Dabrowski et al.,2006; Shashi and Thapar, 2008 ; Atmaca et al.,2014), nephrotoxicity (Kassabi et al., 1981; Kassabi and Braun, 1985; Nabavi et al., 2012) and thyroditis (Leite Ade et al., 2007; Wang et al., 2009).

The observed damage of hepatocytes, renal cells and follicle epithelial cells supported the findings of Godfrey and Watson (1988) who reported apparent inhibition of the synthesis of DNA, protein and cell replication of rat neuronal cells post-fluoride intoxication.

The observed organs dysfunction were reflected on the development of offspring maternally intoxicated with fluoride. The main congenital malformations explained by decreased body weight, kyphotic body, deformation of fore-\&hind limb, kinky tail and reduction of neck region. The overall retarded body growth was assessed by delayed ossification of phalanx and caudal vertebrae and comparatively decreased ossified limb regions and flat bones of skull.

Similar growth deformities of fetuses and increased rates of resorption (Guna sherlin et al., 1999) and skeletal malformations were reported in rat fetuses maternally intoxicated with sodium fluoride (Collins et al., 1995).

Fluoride- intoxication was found to result from absorption of its soluble inorganic components via gastrointestinal tracts and converted to hydrogen fluoride by the acidic environment of the stomach (Whitford and pashley, 1984) and distributed rapidly by the blood 

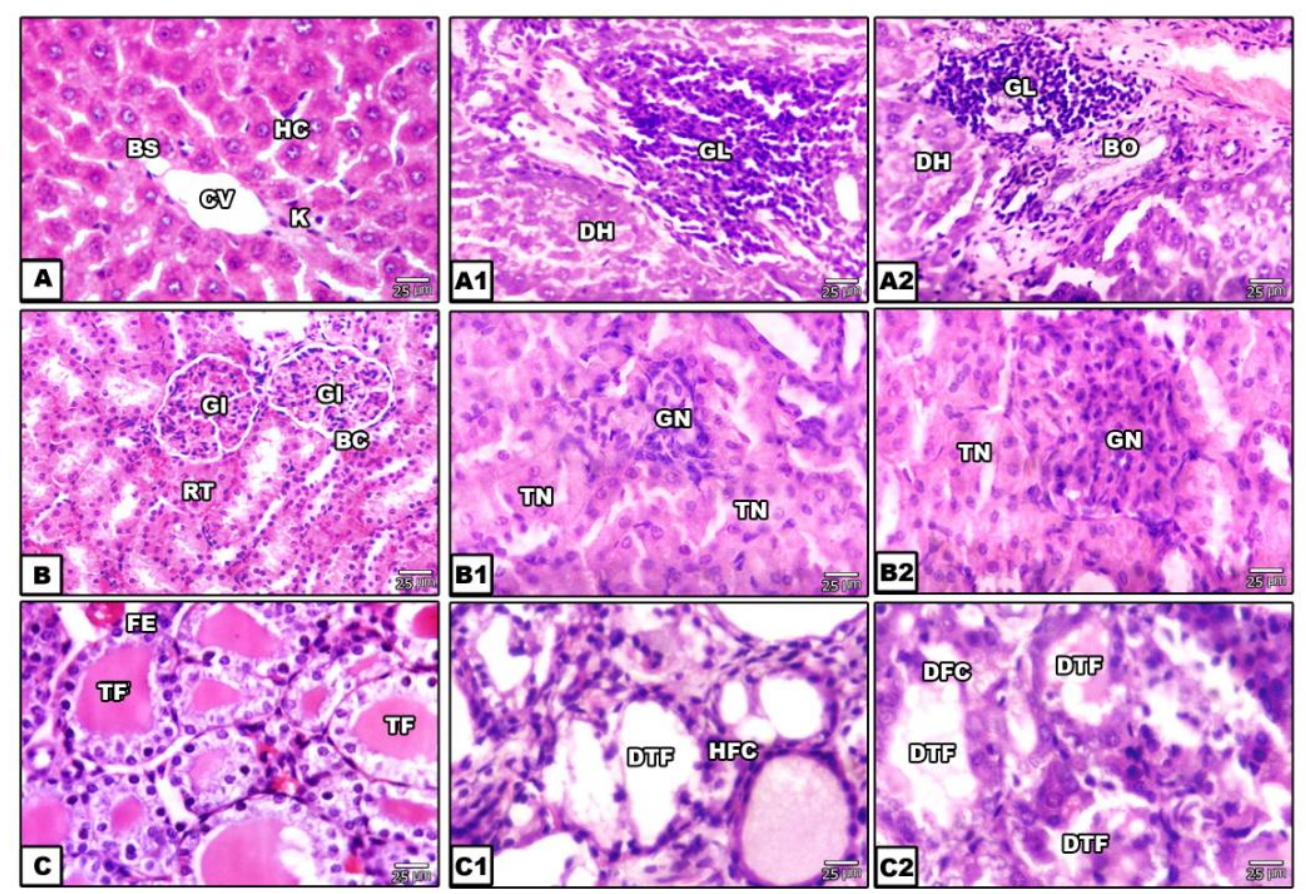

Fig.1. Photomicrographs of liver (A-A2), kidney (B-B2) and thyroid gland (C-C2) of mother rats. A-C. Control. A\&A1, B\&B1 , C\&C1. Fluoride-intoxicated. Note normal pattern structure of hepatic cord and hepatocyte (A), normal renal tubules lined with epithelium and intact glomeruli with Bowmans capsule (B) and regular pattern of thyroid follicles containing thyroglobulin within their lumina (C).A1\&A2. Fluoride-intoxicated hepatic tissues showing granulomatous lesions and bile duct obliterations. B1\&B2. Fluoride intoxicated kidney showing glomerulo-nephrosis and tubular necrosis. C1\&C2. Fluoride-intoxicated thyroid gland showing degenerated epithelium lining the follicles and missing thyroglobulin. H\&E X400

Abbreviations;BC, Bowman capsule; BO, Bile duct obliteration; BS, Blood sinusoids; CV, central vein;DH degenerated hepatocyte,; DFC, degenerated follicle cells; DTF,degenerated thyroid follicle;FE, Follicle epithelium; Gl,Glomeruli ; GL, Granulomatous lesions; GN, Glomerulo-nephritis;HC, Hepatic cord; HFC, , Hemorrhagic follicle cells; RT,Renal tubule; TF, Thyroid follicle; TN, Tubulo-necrosis.

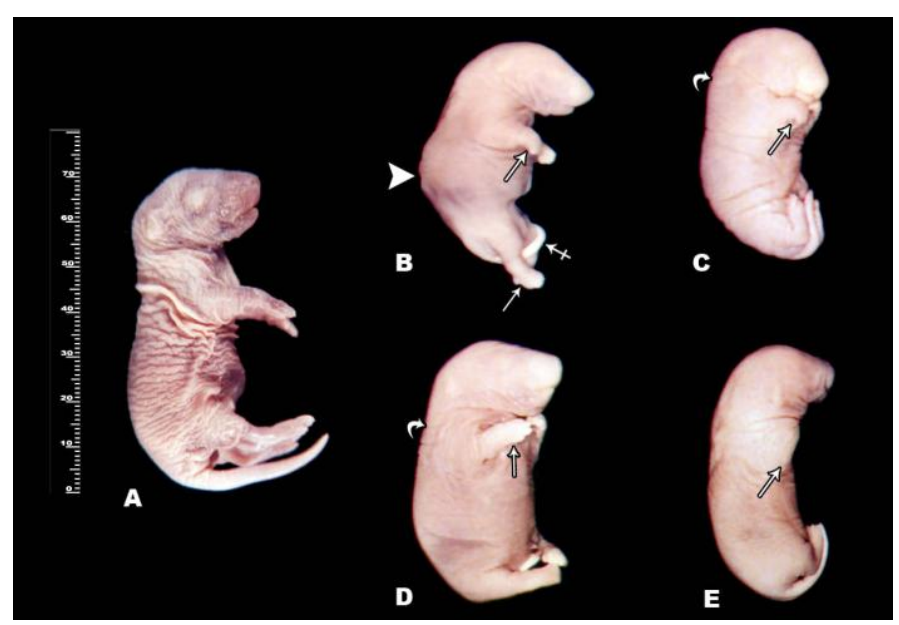

Fig.2. lateral view of gross morphology of newly born 1 day-old of control (A) and maternally intoxicated with fluoride (B-E). B-Showing kyphotic bodym malformed hind limb and kinky tail. C. Showing missing neck regionm deformities gf fore-and hind limb and kinky tail. D. Showing mucinous body and kinky tail. E. Showing deformities fore \& hind limb and kinky tail. 


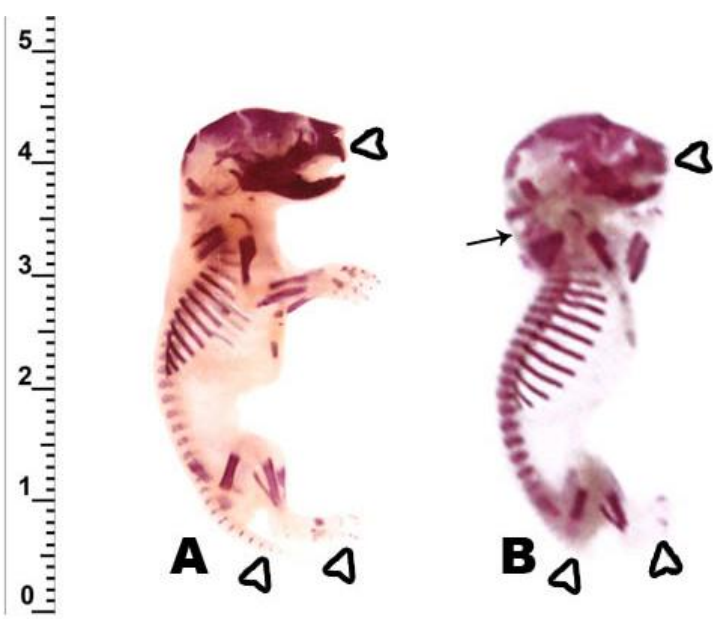

Fig.3. lateral view alizarin preparation of skeleton of newly born 1 day-old of control (A) and maternally intoxicated with fluoride (B). Arrow head indicated delayed bone formation of nasal , sacral and distal phalanges of hind limb.

Table 1. Teratogenicity of rat newly born maternally treated with fluoride from 6th day of gestation till parturition.

\begin{tabular}{|c|c|c|}
\hline & Control & Floride-treatment \\
\hline Total No. of mother & 6 & 6 \\
\hline Aborted mothers & - & 1 \\
\hline Total No. of mother undergoing pregnancy & 6 & $5(83.3 \%)$ \\
\hline Total number of newborn & 49 & $34(69.4 \%)$ \\
\hline Mean number/dam & 8.2 & $6.8(82.9 \%)$ \\
\hline Superfacial haematoma & - & $4(11.8 \%)$ \\
\hline Malformed fore limb & - & $7(20.6 \%)$ \\
\hline Malformed hind limb & - & 6(17.6\%) \\
\hline Reduced neck region & - & $5(14.7 \%)$ \\
\hline Kyphotic body & - & $8(23.5 \%)-$ \\
\hline Deformed neck region & - & $5(14.7 \%)$ \\
\hline Missing Caudal ossification & - & $12(35.4 \%)$ \\
\hline Mean body weight (gm) & $5.6 \pm 0.2$ & $4.2 \pm 0.3$ \\
\hline Mean body size $(\mathrm{cm})^{3}$ & $5.7 \pm 0.6$ & $4.7 \pm 0.4$ \\
\hline Crown-rump length (mm) & $45.3 \pm 2.5$ & $38.4 \pm 3.7$ \\
\hline
\end{tabular}

Each result represent the mean $\pm \mathrm{SE}(\mathrm{n}=10)$. The data is significant at $\mathrm{P}<0.05$.

circulation to the intra-and extracellular tissues as well as accumulated in bone and renal tissues, exerted its cytotoxicity (Taves et al., 1983).

The observed congenital malformation may be attributed to transplacental passage of fluoride (Malhotra et al., 1993; Opydo-Szymaczek and Borysewicz-Lewicka, 2007) and incorporation into foetal tissues retarding bone differentiation. Also, the observed hepatitis may be associated with increased 7-dehydrocholesterol reductase hepatic gene expression, leading to depletion of $25-\mathrm{OH}$ vitamin D serum levels. These were associated with high active transforming growth factor-beta (TGF- $\beta$ ) serum levels, impairing osteoblast function in vitro (Nussler et al., 2014).Cirrhotic liver was found to be associated with reduction of tibial bone. volume leading to osteoporosis (Nakano et al.,1996).

In addition, thyroid hormone (T3) is important for postnatal skeletal growth via binding to nuclear receptors, TRs including TR $\alpha 1$ and TR $\beta 1$, which are important for endochondral bone formation by the cell types chondrocytes and osteoblasts (Desjardin et al., 2014; Tuchendler and Bolanowski, 2014).Expose stage 55 premetamorphic Xenopus larvae to sodium fuoride intoxication at $10 \mathrm{mmol} / \mathrm{L}$ led to decrease the expression of the pro-osteoclastogenic factor RANKL and increase the expression of the anti-osteoclastogenic factor osteoprotegerin. These led to marked alterations of osteoblast and osteoclast differentiation, as well as on the expression of osteoblast products, including MMP1 and collagen (Nair et al., 2011). These may be associated with altered ossification in newly born maternally intoxicated with fluoride.

Finally the author concluded that be avoid of dental team as a result of maternal intoxication.

\section{References}

Atmaca N, Atmaca HT, Kanici A, Anteplioglu T.(2014). Protective effect of resveratrol on sodium fluoride-induced oxidative stress, hepatotoxicity and neurotoxicity in rats. Food Chem Toxicol. 70:191-7. 
Collins TFX, Sprando RL, Shackelford ME, Black TN, Ames MJ, Welsh JJ, et al.(1995). Developmental toxicity of sodium fluoride in rats.Food Chem Toxicol 33: 951-960.

Dabrowska E., Letko R., Balunowska M., (2006). Effect of sodium fluoride on the morphological picture of the rat liver exposed to $\mathrm{NaF}$ in drinking water. Advances in Medical Sciences 51, 91-95.

Desjardin C, Charles C, Benoist-Lasselin C, Riviere J, Gilles M, Chassande O, Morgenthaler C, Laloé D, Lecardonnel J, Flamant F, Legeai-Mallet L, Schibler L.(2014). Chondrocytes play a major role in the stimulation of bone growth by thyroid hormone. Endocrinology. 155(8):3123-35.

Godfrey PP and Watson SP.(1988). Fluoride inhibits agonist-induced formation of inositol phosphates in rat cortex. Biochem Biophys Res Commun. 155:664.

Goh EH , Neff AW.(2003). Effects of fluoride on Xenopus embryo development. Food Chem Toxicol.;41(11):1501-8.

Guna sherlin DM, Verma RJ, Jacob K.(1999). Embryotoxicity of fluoride in rat. Indian J Environ Toxicol; 9: 27-29.

Gupta RS, Khan TI, Agrawal D, Kachhawa JB.(2007).The toxic effects of sodium fluoride on the reproductive system of male rats.Toxicol Ind Health. ;23(9):507-13.

Kassabi M, Braun JP, Burgat-Sacaze V, Bénard P, Rico AG.(1981). Comparison of sodium and stannous fluoride nephrotoxicity. Toxicol Lett.7(6):463-7.

Kessabi M, Braun JP.(1985). .Nephrotoxicity of sodium fluoride. Effect of aluminum sulfate. J Toxicol Clin Exp. 5(4):239-47.

Kumar N, Sood S, Arora B, Singh M, Beena.Effect of duration of fluoride exposure on the reproductive system in male rabbits.J Hum Reprod Sci. 2010 ;3(3):148-52.

Leite Ade L, Santiago JF Jr, Levy FM, Maria AG, Fernandes Mda S, Salvadori DM, Ribeiro DA, Buzalaf MA. (2007)..Absence of DNA damage in multiple organs (blood, liver, kidney, thyroid gland and urinary bladder) after acute fluoride exposure in rats. Hum Exp Toxicol.;26(5):435-40.

Malhotra A, Tewari A, Chawla HS, Gausa K, Dhall K.(19993). Placental transfer of fluoride in pregnant women consuming optimum fluoride in drinking water. J Indian Soc Pedod Prev Dent; 11(1): 1-3.

Nabavi SF, Moghaddam AH, Eslami S, Nabavi SM.(2012). Protective effects of curcumin against sodium fluoride-induced toxicity in rat kidneys. Biol Trace Elem Res. 145(3):369-74.

Nair M, Belak ZR , Ovsenek N.(2011). Effects of fluoride on expression of bone-specific genes in developing Xenopus laevis larvae. Biochem. Cell Biol.89: 377-386.

Nakano A, Kanda T, Abe H.(1996). .Bone changes and mineral metabolism disorders in rats with experimental liver cirrhosis. J Gastroenterol Hepatol. 11(12):1143-54.

Nussler AK, Wildemann B, Freude T, Litzka C, Soldo P, Friess H, Hammad S, Hengstler JG, Braun KF, Trak-Smayra V, Godoy P, Ehnert S.(2014). Chronic $\mathrm{CCl}_{4}$ intoxication causes liver and bone damage similar to the human pathology of hepatic osteodystrophy: a mouse model to analyse the liver-bone axis. Arch Toxicol. 88(4):997-1006.

Opydo-Szymaczek J, Borysewicz-Lewicka M.

(2007). Transplacental passage of fluoride in pregnant polish women assessed in the basis of fluoride concentrations in maternal and cord blood plasma. Fluoride 40(1): 46-50.

Perumal E, Paul V, Govindarajan V, Panneerselvam L. (2013).A brief review on experimental fluorosis. Toxicol Lett. 223(2):236-51.

Pratusha NG, Banji OJF, Banji D, Ragini M, Pavani B.(2011). Fluoride toxicity-A harsh reality. Int. Res. J. Pharm. 2(4):79-85.

Shashi A, Thapar SP.(2000). Histopathology of fluoride-induced hepatotoxicity in rabbits. Fluoride 34(1): 34-42.

Shashi A., Thapar S.P., (2008). Histopathology of fluoride-induced hepatotoxicity in rabbits. Fluoride 41, 4451.

Sun Z, Niu R, Wang B, Jiao Z, Wang J, Zhang J, Wang S, Wang J. (2011).Fluoride-induced apoptosis and gene expression profiling in mice sperm in vivo.Arch Toxicol. 85(11):1441-52.

Susheela A.K., (1999). Fluorosis management programme in India. Current Science, 77, 1250-1256

Taves D, Forbes N, Silverman D, Hicks D.(1983). Inorganic fluoride concentrations in human and animal tissues,in fluorides: effects on vegetation, animals and humans.edited by J Shupe,H Peterson,\&N leone,(paragon Press, Salt Lake city, Utah), P189 .

Thrane EV, Refsnes M, Thoresen GH, Låg M, Schwarze PE.(2001). Fluoride-induced apoptosis in epithelial lung cells involves activation of MAP kinases p38 and possibly JNK. Toxicol Sci. 61(1):83-91.

Tuchendler D, Bolanowski M.(2014). The influence of thyroid dysfunction on bone metabolism. Thyroid Res. $7(1): 12$.

Wang H, Yang Z, Zhou B, Gao H, Yan X, Wang J..(2009).Fluoride-induced thyroid dysfunction in rats: roles of dietary protein and calcium level. Toxicol Ind Health. 25(1):49-57.

Whitford GM, Pashley DH.(1984). Fluoride absorption: The influence of gastric acidity. Calcif. Tissue Int. 36:302.

Zhang B, Wu D.(1998). Effect of fluoride on proliferation and differentiation in rat and mouse embryo bud cell in vitro.Hua Xi Yi Ke Da Xue Xue Bao. 29(3):256-8, 268. 